\title{
FORMULASI NUTRASEUTIKAL GUMMY CANDIES SARI BUAH BELIMBING WULUH (Averrhoa bilimbi L.)
}

\section{FORMULATION NUTRITIONIST GUMMY CANDIES JUICE STARFRUIT (Averrhoa bilimbi L.)}

\author{
Reza Aditya Sunaryo ${ }^{1 *}$, Mohammad Zaky ${ }^{1}$, La Ode Akbar Rasydy ${ }^{1}$ \\ ${ }^{1}$ Sekolah Tinggi Farmasi Muhammadiyah Tangerang \\ ${ }^{*}$ Corresponding Author Email: rezalfn06@gmail.com \\ DOI: http://dx.doi.org/10.47653/farm.v7i2.478
}

\begin{abstract}
ABSTRAK
Belimbing wuluh (Averrhoa bilimbi L.) merupakan salah satu tanaman buah dari keluarga (Oxalidaceae) dengan marga (Averrhoa). Buah belimbing wuluh memiliki daya simpan yang relative singkat sekaligus memiliki rasa asam sehingga kurang disukai jika dikonsumsi secara langsung. Penelitian ini bertujuan untuk mengetahui bahwa sari buah belimbing wuluh (Averrhoa bilimbi L.) dapat dibuat menjadi sediaan nutraseutikal gummy candies serta dapat mengetahui formula manakah yang paling disukai responden dan hasil evaluasi fisik yang terbaik dalam sediaan gummy candies. sampel berupa buah belimbing wuluh dilakukan dengan metode spray drying yang diformulasikan menjadi sediaan gummy candies dengan variasi konsentrasi sukrosa $115 \mathrm{mg}, 230 \mathrm{mg}, 345 \mathrm{mg}, 490 \mathrm{mg}, 575 \mathrm{mg}$. semua sediaan di uji dengan pengujian organoleptis, keseragaman bobot dan hedonik. Hasil dari evaluasi sediaan gummy candies menyatakan bahwa sediaan gummy candies memenuhi mutu fisik. Dari data tersebut dapat disimpulkan bahwa sediaan gummy candies sari buah belimbing wuluh menunjukkan hasil uji yang paling disukai dari sediaan gummy candies yaiitu pada formula 3 dengan kadar sukrosa $345 \mathrm{mg}$ berdasarkan parameter rasa, warna, aroma dan bentuk.hasil dari uji keseragaman bobot yaitu pada formula 3 yang paling disukai panelis.
\end{abstract}

Kata Kunci: Buah Belimbing Wuluh, Gummy Candies

\section{ABSTRACT}

Starfruit (Averrhoa bilimbi L.) is one of fruit plants from family (Oxilidaceaae) with clan (Averrhoa). Starfruit have storability which is relative short at once have sour taste so less preferred if consumed directly. This research aim to determine that starfruit juice (Averrhoa bilimbi L.) nutronist gummy candies juice starfruit (Averrhoa bilimbi L.) can be made into a nutritional preparation gummy candies and can find out which formula the respondent most like and the results of the best physical evaluation in the preparation of gummy candies. Sample in the from performed with method spray drying which is formulated into preparations gummy candies with variations in concentration sucrose 115, 230, 340, 499, $575 \mathrm{mg}$. all preparatuins are tested by testing :organoleptic test, uniformity of weights and hedonic. The results of the evalution of the preparation gummy candies state that the preparation gummy candies meet physical quality. From these data it can be concluded that the preparation of gummy candies juice starfruit shows the most preferred test results from the preparation gummy candies that is in formula 3 with $345 \mathrm{mg}$ based sucrose content parameter of the flavor colir, aroma and shape. The results of the weight uniformity test is formula 3 which is the most preferred.

Keywords: Starfruit, Gummy Candies

\section{PENDAHULUAN}

Indonesia merupakan negara dengan keaneragaman hayati yang melimpah, hampir berbagai jenis tumbuhan dapat tumbuh baik di negara ini. Sebagian besar telah dimanfaatkaan sejak jaman nenek moyang untuk mengobati berbagai penyakit, dimana tumbuhan tersebut penggunaannya dikenal sebagai obat tradisional. Indonesia memiliki jumlah penduduk yang sebagian masyarakat masih tinggal dipedesaan, namun disekitar lingkungan terdapat tumbuhan yang berkhasiat sebagai obat tradisional, khususnya pada tanaman belimbing wuluh. Paling sering 
digunakan yaitu buahnya. Dimana buah belimbing wuluh bisa dipakai untuk penyedap rasa asam pada masakan sekaligus bermanfaat untuk mengobati seperti batuk, demam, sariawan, gusi berdarah, jerawat, panu dan tekanan darah tinggi ( BPOM RI, 2013).

Belimbing wuluh (Averrhoa bilimbi L.) merupakan salah satu tanaman buah dari keluarga (Oxalidaceae) dengan marga (Averrhoa). Buah belimbing wuluh memiliki daya simpan yang relative singkat sekaligus memiliki rasa asam sehingga kurang disukai jika dikonsumsi secara langsung.

Tanpa disadari, tubuh manusia setiap harinya terpapar beragam racun, polusi, makanan tak sehat, obat-obatan, stress dan sebagainya, maka perlu dihimbau untuk mengkonsumsi nutrisi yang cukup seperti vitamin, mineral yang terkandung dalam buah dan sayur. Dalam dunia industry kesehatan telah membuat sediaan suplemen terus berkembang dari suplemen telah muncul nutraseutikal.

Nutraseutikal adalah produk suplemen makanan atau herbal yang dapat memberikan manfaat bagi kesehatan dalam pencegahan dan pengobatan penyakit yang berasal dari bahan-bahan alami, selain itu bentuk nutraseutikal bermacam-macam ada vitamin dan mineral dengan dosis relative besar seperti orthomolecular, mikronutrien dan sebagainya. Nutraseutikal yang beredar di masyarakat cenderung mahal, tidak terlalu bervariasi, sediaan ini dalam bentuk tablet effervescent dan minuman kesehatan maka respon masyarakat menuntut penggunaan nutraseutikal yang murah dan penggunaan nya praktis, khusus nya membuat sediaan formulasi gummy candies dari sari buah belimbing wuluh (Syamsudin, 2013).

Gummy candies atau permen jelly yaitu suatu sediaan produk manisan yang berbentuk lunak seperti jelly yang dibuat dari campurancampuran bahan berupa air atau sari buah dan bahan pembentuk gel serta dengan tambahan bahan pemanis, berpenampilan jernih transparan serta memiliki tekstur dengan kekenyalan tertentu. Bahan pembentukan gel yang biasa digunakan yaitu gelatin, karagenan, agar-agar serta bahan pemanis ada sukrosa, laktosa, glukosa dan sebagainya (Koswara, 2009).

Bahan pemanis yang sering digunakan membuat gummy candies yaitu sukrosa. Sukrosa merupakan suatu disakarida yang dibentuk dari monomer-monomer yang berupa unit glukosa dan fruktosa dengan rumus $\mathrm{C}_{12} \mathrm{H}_{22} \mathrm{O}_{11}$. Sukrosa memiliki kandungan kalori yang cukup tinggi yaitu sebesar 400 kalori dalam 100 gram bahan, maka sukrosa dapat berfungsi sebagai bahan pengisi, bahan pengikat sekaligus berfungsi sebagai bahan pengawet (Armstrong, 2005). Keuntungan dari sediaan gummy candies ini sangat disukai karena mempunyai warna, bau dan rasa serta bentuk yang menarik dan mudah dikunyah.

Menurut penelitian yang dilakukan oleh Sari et al pada tahun 2013 sediaan gummy candies formula 3 dengan perbandingan basis manitol dan corn syrup (25\%:75\%) memiliki bentuk, warna, rasa, bau, dan tekstur paling baik dibandingkan dengan formula lainnya. Selain itu pada penelitian yang dilakukan oleh Kresnanto et al pada tahun 2013 disimpulkan bahwa hasil sifat fisik gummy candies dengan variasi kadar sukrosa sebagai bahan pemanis tidak mempengaruhi keseragaman bobot dan pada formula 4 dengan kadar variasi sukrosa sebagai bahan pemanis sebesar $17,96 \%$ merupakan formula paling disukai oleh responden.

Berdasarkan uraian diatas, maka perlu dilakukan penelitian untuk melakukan studi Formulasi Nutraseutikal Gummy Candies dari Sari Buah Belimbing Wuluh (Averrhoa bilimbi L.).

\section{METODOLOGI PENELITIAN Alat}

Alat yang akan digunakan membuat sari buah : blender, penyaring, Spray Dryer, beaker glass $250 \mathrm{~mL}$ (Pyrex® IWAKI, Japan), gelas ukur $10 \mathrm{~mL}$ (Pyrex® IWAKI, Japan), gelas ukur 100 mL (Pyrex® IWAKI, Japan), bunsen, kaki tiga, kawat kasa, batang pengaduk, kaca arloji, penjepit tabung, neraca elektrik, cetakan permen, spatula, cawan porselin, pipet tetes, dan Loyang.

\section{Bahan}

Bahan yang akan digunakan yaitu buah belimbing wuluh akan menjadikan sari buah (Lux Chemicals, Indonesia), sirup jagung (Lux Chemicals, Indonesia), gelatin (Eurotrade World Commerce S.L, Madrid [Spanyol], gom arab (Making Cosmetics, Washington [Amerika Serikat], laktosa (GRANDE Custom Ingredients Group, Amerika Serikat), sukrosa (Avantor, Amerika Serikat), manitol (QINDAO BRIGHT MOON SEAWEED GROUP CO, China), Purified Water. 


\section{Pembuatan Bubuk Sari Buah Belimbing Wuluh (Averrhoa bilimbi L.)}

Pembuatan bubuk sari buah di awali dengan pengambilan buah belimbing wuluh mendapatkan sebanyak $2 \mathrm{~kg}$, kemudian lanjutkan proses sortasi pada buah lalu dicuci hingga bersih. Selanjutnya bila buah sudah bersih kemudian lanjutkan proses pemblenderan, bila buah sudah diblender lalu pisahkan dengan penyaring untuk mendapatkan hasil sari buahnya, hasil sari buah mendapatkan $500 \mathrm{ml}$. kemudian lanjutkan dengan proses pengeringan semprot dengan alat spray drying untuk mendapatkan hasil bubuk sari buahnya, proses pengeringan nya dilakukan dengan suhu $150^{\circ} \mathrm{C}$ hingga menjadi hasil nya menjadi serbuk. Hasil yang didapatkan dari serbuk sari buah belimbing wuluh mendapatkan $32,2 \mathrm{~g}$.

\section{Pembuatan Gummy Candies Sari Buah} Belimbing Wuluh (Averrhoa bilimbi L.)
Ditimbang manitol, sirup jagung, laktosa, sukrosa, gelatin, dan purified water sesuai perhitungan. Pembuatan basis gummy masukkan manitol dan sirup jagung kedalam porselin lalu diisikan dengan purifield water kemudian dipanaskan menggunakan waterbatch pada suhu $80^{\circ} \mathrm{C}$ hingga melebur sempurna.

Larutkan gom arab didalam $10 \mathrm{ml}$ purified water panas pada beaker gelas yang terpisah, Memanaskan $15 \mathrm{ml}$ purified water panas, masukkan gelatin yang sudah aktif (larut) kedalam larutan gom arab aduk ad homogen. Tambahkan sari buah belimbing wuluh di aduk ad homogen, tambahkan sukrosa aduk ad homogen. Tambahkan laktosa ke dalam campuran lalu aduk ad homogen. Semua bahan tambahan dimasukkan ke dalam campuran di aduk secara perlahan tanpa menimbulkan adanya buih kemudian aduk sampai homogen, campuran tersebut dituangkan kedalam cetakan dan dinginkan. Kemudian sebelum dikemas maka akan dilakukan uji sifat fisik.

Tabel 1. Formulasi Sediaan Gummy Candies

\begin{tabular}{lcccccc}
\hline Bahan $(\mathbf{m g})$ & $\mathbf{F . 1}$ & $\mathbf{F . 2}$ & $\mathbf{F . 3}$ & $\mathbf{F . 4}$ & $\mathbf{F . 5}$ & Kegunaan \\
\hline Sari buah & 300 & 300 & 300 & 300 & 300 & Sampel sediaan buah \\
Manitol & 190 & 190 & 190 & 190 & 190 & Bahan pengencer, bahan pemanis \\
Corn syrup & 538,65 & 538,65 & 538,65 & 538,65 & 538,65 & Agen pelapis, bahan pemanis, bahan pengikat \\
Gelatin & 760 & 760 & 760 & 760 & 760 & Bahan pengikat, bahan pengisi \\
Gom arab & 28,5 & 28,5 & 28,5 & 28,5 & 28,5 & Bahan pengikat \\
Laktosa & 190 & 190 & 190 & 190 & 190 & Bahan pengisi \\
Sukrosa & 115 & 230 & 345 & 490 & 575 & Bahan penyalut, bahan pengisi, bahan pemanis \\
\hline
\end{tabular}

Keterangan :

Sediaan F1 : Formula dengan konsentrasi sukrosa 115

Sediaan F2 : Formula dengan konsentrasi sukrosa 230

Sediaan F3 : Formula dengan konsentrasi sukrosa 345

Sediaan F4 : Formula dengan konsentrasi sukrosa 490

Sediaan F5 : Formula dengan konsentrasi sukrosa 575

\section{Evaluasi Fisik}

Pengujian evaluasi fisik dilakukan setelah sediaan gummy candies sari buah belimbing wuluh (Averrhoa bilimbi L.) Pengujian yang dilakukan meliputi :

\section{Uji Organoleptis}

Uji ini dilakukan dengan cara dilihat dari bentuk, warna, bau, dan rasa.

\section{Uji Keseragaman Bobot}

Sejumlah 20 tablet ditimbang, hitung bobot rata-rata tiap tablet, jika ditimbang satu per satu tidak boleh dari dua tablet yang bobotnya menyimpang lebih besar dari bobot rata-rata yang ditetapkan kolom A dan tidak satu pun yang bobotnya menyimpang dari bobot rata-rata yang ditetapkan pada kolom B. harga koefisiensi variasi (CV) dihitung dengan menggunakan rumus :

$$
C V=\frac{\mathrm{SD}}{X} x 100 \%
$$

Tabel 2. Persyaratan Penyimpangan Bobot

Tablet (Anonim,2014) 


\begin{tabular}{ccc}
\hline Bobot rata-rata & \multicolumn{2}{c}{$\begin{array}{c}\text { Penyimpangan bobot } \\
\text { rata-rata }\end{array}$} \\
\cline { 2 - 3 } & A & B \\
\hline $25 \mathrm{mg}$ atau kurang & $15 \%$ & $30 \%$ \\
$26 \mathrm{mg}-150 \mathrm{mg}$ & $10 \%$ & $20 \%$ \\
$151 \mathrm{mg}-300 \mathrm{mg}$ & $7,5 \%$ & $15 \%$ \\
Lebih dari $300 \mathrm{mg}$ & $5 \%$ & $10 \%$ \\
\hline
\end{tabular}

\section{Uji Hedonik}

Uji kesukaan pada dasar nya merupakan pengujian yang panelis nya menggunakan respon berupa senang atau tidaknya terhadap bahan yang diuji. Pada penelitian ini dilakukan uji kesukaan terhadap 20 responden dari berbabgai usia dengan parameter yang diuji meliputi rasa, aroma, warna, dan bentuk serta tingkat kesukaaan responden terhadap setiap formula. Skala nilai numeric dengan nilai 1 sampai 3. Nilai 1 menyatakan tidak suka, nilai 2 menyatakan suka, dan nilai 3 menyatakan sangat suka.

\section{ANALISIS DATA}

Data yang diperoleh dalam penelitian ini dianalisis menggunakan metode deskriptif, metode deskrptif ini menggambarkan suatu keadaan yang objektif, dengan metode ini data yang diperoleh dapat disajikan dalam bentuk tabel, grafik maupun persentase untuk uji evaluasi fisik sediaan.

\section{HASIL DAN PEMBAHASAN Identifikasi Tanaman}

Berdasarkan identifikasi tanaman yang dilakukan di Hebarium Bogoriense, Pusat Penelitian Biologi LIPI, Bogor, Jawa Barat menunjukkan bahwa tanaman yang digunakan adalah tanaman belimbing wuluh (Averrhoa bilimbi L.) dari Family Oxalidaceae.

\section{Hasil Organoleptis Spray Drying Sari Buah Belimbing Wuluh}

Tabel 3. Hasil Orrganoleptis Sari Buah Belimbing Wuluh (Averrhoa bilimbi L.)

\begin{tabular}{ccc}
\hline No & $\begin{array}{c}\text { Pemeriksaan } \\
\text { Organoleptis }\end{array}$ & Hasil \\
\hline 1 & Bentuk & $\begin{array}{c}\text { Serbuk } \\
\text { Putih rada } \\
\text { keruh } \\
\text { Khas buah } \\
\text { belimbing } \\
\text { wuluh } \\
\text { Sangat } \\
\text { asam }\end{array}$ \\
\hline
\end{tabular}

Spray drying atau pengeringan semprot merupakan proses satuan operasi dimana di dalamnya produk cair diatomisasi dalam aliran gas panas untuk secara instan mendapatkan bubuk. Dimana proses tersebut akan memerlukan dengan suhu sekitar $150-220^{\circ} \mathrm{C}$ (Gharsallaoui et al., 2007). Selanjutnya setelah proses pengeringan semprot telah selesai kemudian mendapatkan hasil serbuk sebanyak 32,2 g dari panen buah belimbing wuluh sebanyak $2 \mathrm{~kg}$.

\section{Hasil Evaluasi Fisik Sediaan Gummy Candies \\ 1. Uji Organoleptis}

Pengamatan organoleptis ini dilakukan secara visual dengan melihat tampilan fisik suatu sediaan yang meliputi rasa, warna, aroma/ bau dan tekstur/ bentuk.

Tabel 4. Hasil Uji Organoleptis Formulasi Sediaan Gummy Candies Sari Buah Belimbing Wuluh

\begin{tabular}{|c|c|c|c|c|}
\hline Formula & Rasa & Warna & Bau & Bentuk \\
\hline$\overline{F 1}(115 \mathrm{mg})$ & $\begin{array}{l}\text { Asam dan tidak } \\
\text { ada rasa }\end{array}$ & $\begin{array}{c}\text { Kuning } \\
\text { kecoklatan }\end{array}$ & $\begin{array}{c}\text { Khas buah } \\
\text { belimbing wuluh }\end{array}$ & Beruang, kenyal \\
\hline F2 (230 mg) & $\begin{array}{l}\text { Asam sedikit } \\
\text { manis }\end{array}$ & $\begin{array}{c}\text { Kuning } \\
\text { kecoklatan }\end{array}$ & $\begin{array}{l}\text { Khas buah } \\
\text { belimbing wuluh }\end{array}$ & Beruang, kenyal \\
\hline F3 (345 mg) & Sedikit manis & $\begin{array}{c}\text { Kuning } \\
\text { kecoklatan }\end{array}$ & $\begin{array}{l}\text { Khas buah } \\
\text { belimbing wuluh }\end{array}$ & Beruang, kenyal \\
\hline F4 (490 mg) & Manis & $\begin{array}{c}\text { Kuning } \\
\text { kecoklatan }\end{array}$ & $\begin{array}{l}\text { Khas buah } \\
\text { belimbing wuluh }\end{array}$ & Beruang, kenyal \\
\hline F5 (575 mg) & Manis-manis asam & $\begin{array}{c}\text { Kuning } \\
\text { kecoklatan }\end{array}$ & $\begin{array}{l}\text { Khas buah } \\
\text { belimbing wuluh }\end{array}$ & Beruang, kenyal \\
\hline
\end{tabular}




\begin{abstract}
Berdasarkan Tabel 4 hasil pengamatan uji organoleptis dengan menggunakan alat indera oral menunjukan bahwa setiap formula sediaan gummy candies sari buah belimbing wuluh (Averrhoa bilimbi L.) pada 5 formula gummy candies sari buah belimbing wuluh dalam secara pengamatan fisik lebih menarik dari 3 formula lainnya yaitu formula 4 dan formula 5 . Kedua formula tersebut jika dilihat pengamatan visual lebih baik dibandingkan dengan formula 1 , formula 2 , formula 3. 2 formula tersebut hamper sempurna dan tidak memiliki kecacatan dalam bentuk fisik, secara rasa pada formula 4 dan formula 5 lebih berasa manis dan memiliki bentuk tekstur yang sangat kenyal sedangkan ke 3 formula tersebut untuk rasa lebih condong sedikit asam yaitu pada formula 1 , formula 2 , formula 3 , dan untuk bentuk atau tekstur tidak begitu kenyal. Untuk warna dan aroma pada 5 formula tersebut hampir sama semua Karena kelima formula ini memiliki warna kuning agak kecoklatan dan aroma khas buah belimbing wuluh.
\end{abstract}

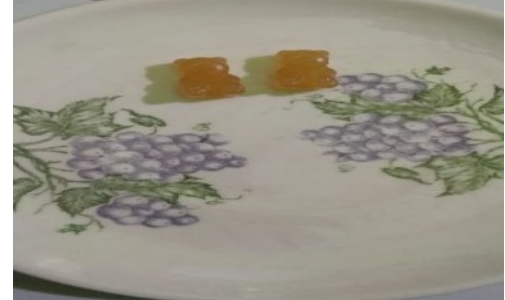

Gambar 1. Formula Gummy Candies

\section{Uji Keseragaman Bobot}

Keseragaman bobot merupakan salah satu syarat yang harus dipenuhi dalam produksi. Pembuatan gummy candies guna untuk mengetahui variasi bobot yang dihasilkan. Keseragaman bobot permen ditentukkan berdasarkan banyak penyimpangan bobot pada tiap permen terhadap bobot rata-rata dari semua permen sesuai syarat yang telah ditentukkan. Hasil evaluasi uji keseragaman bobot tidak menunjukkan perbedaan dari kelima formula. Syarat keseragaman bobot menurut farmakope jika ditimbang harus satu per satu, tidak boleh lebih dari 2 buah permen yang masing-masing bobot nya menyimpang dari bobot rata-ratanya lebih dari $5 \%$ dan tidak satupun permen yang bobotnya yang menyimpang dari bobot rata-ratanya lebih dari 10\% (Depkes RI, 1995).

Tabel 5. Hasil Pengamatan Uji Homogenitas

\begin{tabular}{ccccc}
\hline Formula & \multirow{2}{*}{$\begin{array}{c}\text { Rata-rata bobot } \\
\text { g } \pm \text { SD }\end{array}$} & $\begin{array}{c}\text { Koefisiensi } \\
\text { variasi }\end{array}$ & \multicolumn{2}{c}{ Batas } \\
\cline { 4 - 5 } & & & Bobot seragam sediaan \\
\cline { 4 - 5 } F1 $(115 \mathrm{mg})$ & $1.45 \pm 0.51$ & 2.8 & $1.63-1.47$ & $1.71-1.40$ \\
F2 $(230 \mathrm{mg})$ & $1.35 \pm 0.49$ & 0 & $1.47-1.33$ & $1.54-1.26$ \\
F3 $(345 \mathrm{mg})$ & $1.7 \pm 0.47$ & 0.28 & $3-0$ & $1.65-1.35$ \\
F4 $(490 \mathrm{mg})$ & $1.7 \pm 0.47$ & 0.28 & $1.68-1.52$ & $1.76-1.44$ \\
F5 $(575 \mathrm{mg})$ & $1.7 \pm 0.47$ & 0.28 & $1.58-1.43$ & $1.65-0.15$ \\
\hline
\end{tabular}

Berdasarkan Tabel 5 Dari kelima formula, hasil evaluasi uji keseragaman bobot ini telah memenuhi persyaratan uji keseragaman bobot dikarenakan pada masing-masing formula tidak ada lebih 1 buah gummy candies yang menyimpang dari harga penyimpangan yang ditetapkan kolom A dan kolom B. nilai CV (koefisiensi variasi) yang diperoleh dari perhitungan menunjukkan tidak ada yang lebih besar dari $5 \%$ sehingga dapat memenuhi persyaratan keseragaman bobot.

\section{Uji Tanggapan Responden (Hedonik)}

Penilaian sampel yang akan diuji berdasarkan tingkat kesukaan panelis. Pada jumlah tingkat kesukaan sangatlah bervariasi, dalam penilaian juga segi bentuk, angka dan penarikan kesimpulan (Badan Standar Nasional, 2006). Skala uji hedonic akan digunakan menilai parameter yang dianggap penting dan mengambarkan karakterikstik dari sediaan gummy candies yang akan dipilih. Untuk parameter hedonic tersebut akan diamati oleh panelis-panelis tersebut meliputi parameter rasa, warna , aroma, dan bentuk. Analisi ini dilakukakn dengan menggunakan 20 panelis dengan cara memberikan penilaian terhadapa masing-masing sdiaan gummy candies sari buah belimbing wuluh. Dalam uji tingkat 
kesukaan ini memiliki 3 penilaian yaitu untuk penlaian 1 kategori tidak suka, penilaian 2 kategori suka, dan penilaian 3 kategori sangat suka.

Tabel 6. Hasil Pengamatan Uji Hedonik

\begin{tabular}{|c|c|c|c|c|c|}
\hline \multirow[t]{2}{*}{ Parameter } & \multicolumn{5}{|c|}{ Tanggapan Panelis } \\
\hline & $\overline{F 1}$ & F2 & F3 & F4 & F5 \\
\hline Rasa & 1,28 & 1,59 & 1,8 & 1,65 & 1,87 \\
\hline Warna & 1,86 & 1,93 & 2,43 & 1,95 & 1,84 \\
\hline Aroma & 1,41 & 1,74 & 1,78 & 1,72 & 1,75 \\
\hline Bentuk & 1,98 & 2,35 & 2,02 & 1,95 & 2,02 \\
\hline
\end{tabular}

Keterangan :

1 : Tidak Suka

2: Suka

3 : Sangat Suka

Berdasarkan Tabel 6 hasil pengamatan diketahui formula yang lebih disukai oleh panelis adalah formula 3 dengan konsentrasi sukrosa $345 \mathrm{mg}$. Hal ini ditunjukkan oleh nilai rata-rata data uji hedonik pada warna, rasa, aroma serta bentuk sediaan dan produk secara keseluruhan yang disukai oleh panelis.

\section{KESIMPULAN}

Berdasarkan hasil penelitian yang telah dilakukan maka sari buah belimbing wuluh (Averrhoa bilimbi L.) dapat diformulasikan sebagai gummy candies. Dari hasil uji hedonik formula 3 menunjukkan bahwa hasil uji yang paling disukai dari sediaan gummy candies sari buah belimbing wulu dengan kadar sukrosa 345 mg berdasarkan parameter warna, aroma, tekstur dan rasa. Dari hasil uji evaluasi fisik sediaan gummy candies sari buah belimbing wuluh ini sediaan terbaik dari 5 formula yaitu formula 3.

\section{SARAN}

Perlu dilakukan penelitian lebih lanjut untuk mengetahui hasil uji stabilitas sediaan gummy candies sari buah belimbing wuluh tersebut dalam durasi waktu untuk mengetahui batas kadarluarsanya sebelum dilakukan produksi dalam skala industri.

\section{DAFTAR PUSTAKA}

Anonim. 2014. Farmakope Indonesia, Edisi V. Departemen Kesehatan Republik Indonesia. Jakarta. Hal 1572

Armstrong, N.A. 2005. Sucrose in rowe C.R., Sheskey, P.J., and Owen, S.C.,(Eds). Handbook of Pharmaceutical Exipients, $5^{\text {th }}$ Edition. London UK. Pharmaceutical Press. Hal 743-747
Badan Standarisasi Nasional. 2006. SNI 012346-2006, Petunjuk Pengujian Organoleptic Atau Sensori. Jakarta. Badan Standarisasi Nasional. Hal 2

BPOM RI. 2013. Dokumentasi Ramuan Etnomedisin Obat Asli Indonesia. Badan Pengawasan Obat dan Makanan Republik Indonesia. Jakarta. Hal 15

Depkes RI. 1995. Farmakope Indonesia IV. Edisi IV. Jakarta. Departemen Kesehatan RI. Hal 12

Gharsallaoui, A., G. Roudat, O. Chambin, A.Voilley, dan R. Saurel. 2007. Applications of Spray-drying in Microencapsulation of Food Ingredients: An overview. Food Research International 40: Hal 1107-1121.

Kresnanto, V. A. Feris Firdaus dan Fajrianto. 2013. Formulasi Nutraseutikal Sediaan Gummy Candies Sari Buah Markisa Kuning (Passiflora edulis var.Flavicarpa) Dengan Variasi kadar Sukrosa Sebagai Bahan Pemanis. Jurnal Universitas Islam Indonesia. Yogyakarta.

Koswara, S. 2009. Teknologi Pembuatan Permen. Ebook Pangan.Com. http://tekpan.unimus.ac.id/wpcontent/uploa ds/2013/07/TEKNOLOGI-

PEMBUATANPERMEN.pdf.Diakses tanggal 27 Oktober 2019.

Rowe, R.C., Paul, J.S. and Marian, E.Q. 2009. Hanbook Of Pharmaceutical Excipients, Sixth Edition. USA. Pharmaceutical Press and American Pharmacixts Asociation. Hal: 199, 278, 282, 364, 424, dan 703.

Sari, E. V. M, Feris Firdaus dan Fajrianto. 2013. Variasi Kadar Manitol dan Corn Syrup Sebagai Basis Dalam Formulasi Nutraseutikal Sediaan Gummy Candies Sari Buah Markisa Kuning (Passiflora 
edulis var.Flavicarpa). Jurnal Universitas

Islam Indonesia. Yogyakarta.

Syamsudin. 2013. Nutrasetikal. Jakarta: Graha

IImu. Hal 1,11-13,73 